\title{
Association between birth weight and risk of abdominal obesity in children and adolescents: a school-based epidemiology survey in China
}

Zhaogen Yang ${ }^{1}$, Bin Dong ${ }^{1}$, Yi Song ${ }^{1}$, Xijie Wang ${ }^{1}$, Yanhui Dong ${ }^{1}$, Di Gao ${ }^{1}$, Yanhui Li ${ }^{1}$, Zhiyong Zou' Jun $\mathrm{Ma}^{1^{*}}$ (D) and Luke Arnold ${ }^{2}$

\begin{abstract}
Background: Abdominal obesity is becoming an increasingly serious public health challenge in children and adolescents, there remains controversial opinions on birth weight and risk of childhood abdominal obesity. This study aims to assess the association between birth weight and the risk of abdominal obesity in childhood, as well as to compare the associations among different sex and age groups.

Methods: A total number of 30,486 (15,869 boys and 14,617 girls) participants aged 6-17years old were included in this study. Participants were classified into five groups according to their birth weight. Waist-to-height ratio (WHtR) was used to define abdominal obesity. Fractional polynomial regression model was used to assess the association between birth weight and $\mathrm{WHtR}$, and a multi-variable logistic regression model was applied to evaluate the risk of abdominal obesity in different birth weight groups.

Results: A J-shaped association was observed between birth weight and WHtR. Compared with birth weight of 2500-2999 g, high birth weight was associated with increased risk of abdominal obesity [OR (95\% Cl) for 3000$3499 \mathrm{g:} 1.12(1.00-1.24) ; 3500-3999 \mathrm{g:} 1.19(1.07-1.34)$; $\geq 4000 \mathrm{~g}: 1.42(1.24-1.62)]$. No significant correlation was observed in children with birth weight $\leq 2499 \mathrm{~g}$. Similar patterns were observed across different age groups. Abdominal obesity risk for high birth weight was particularly pronounced in boys compared to girls.
\end{abstract}

Conclusions: Birth weight $\geq 3000 \mathrm{~g}$, especially for boys, was associated with an elevated risk of abdominal obesity in childhood and may benefit from intervention to mitigate this risk.

\section{Background}

Childhood obesity is one of the most serious public health challenges worldwide [1]. In China, the prevalence of overweight and obesity among school-aged children has increased from $3.0 \%$ in 1985 to $19.4 \%$ in 2014 $[2,3]$. It has been demonstrated that childhood

\footnotetext{
* Correspondence: majunt@bjmu.edu.cn

${ }^{1}$ Institute of Child and Adolescent Health \& School of Public Health, Peking University, No. 38 Xueyuan Road, Haidian District, Beijing 100191, People's Republic of China

Full list of author information is available at the end of the article
}

overweight and obesity increase risk of many adverse health consequences throughout life-course $[1,4,5]$.

Although obesity had been typically defined using body mass index (BMI), it has been demonstrated that BMI has limited capacity in measuring fat distribution [6]. Other anthropometric indices, such as waist-to-height ratio (WHtR) [7-9], are simple and useful indicators of abdominal fat. Compared with BMI, WHtR has been suggested as a superior predictor of obesity related adverse health

(c) The Author(s). 2020 Open Access This article is licensed under a Creative Commons Attribution 4.0 International License, which permits use, sharing, adaptation, distribution and reproduction in any medium or format, as long as you give appropriate credit to the original author(s) and the source, provide a link to the Creative Commons licence, and indicate if changes were made. The images or other third party material in this article are included in the article's Creative Commons licence, unless indicated otherwise in a credit line to the material. If material is not included in the article's Creative Commons licence and your intended use is not permitted by statutory regulation or exceeds the permitted use, you will need to obtain permission directly from the copyright holder. To view a copy of this licence, visit http://creativecommons.org/licenses/by/4.0/ The Creative Commons Public Domain Dedication waiver (http://creativecommons.org/publicdomain/zero/1.0/) applies to the data made available in this article, unless otherwise stated in a credit line to the data. 
consequences [10], including hypertension [11], metabolic syndrome [12], and other cardiovascular disease [13].

It has been suggested that early development (especially in utero) can influence a person's physiology and metabolic health status permanently [14, 15]. Birth weight is considered as a proxy for fetal growth $[16,17]$. Several previous studies have found significant associations between birth weight and abdominal obesity. Ansari [18] reported that high birth weight (>4000 g) was associated with increased risk of abdominal obesity in children aged 6-18 years. Tian [19] and his colleague also found high birth weight $(\geq 3500 \mathrm{~g}$ ) to be a risk factor of abdominal obesity in people at 15-74 years old. Meanwhile, Vohr BR [20] reported that extreme preterm infants had increased risk of abdominal obesity when children entering into 6 to 7 years old. A study from southern England [21] had also found low birth weight to be associated with a tendency of central fat accumulation in 14 to 16 years old girls. However, some other studies [22, 23] did not observe significant correlations, and few had investigated this correlation with continuous variables, but the range of birth weight associated with the higher risk of abdominal obesity remained unclear.

It has also been proposed that the correlations may vary by sex and age. A cross-sectional study in 7 to 8 year-old Japanese children [24] has demonstrated a higher WHtR in girls with birth weight $<3000 \mathrm{~g}$, but not in boys. Rodríguez Vargas N [22] found that high birth weight was not a predictive factor for abdominal obesity in 7-11 years old children, while another study found high birth weight to be a risk factor of abdominal obesity in 6 to 18 year-old children [18]. In summary, there was still a considerable lack of research regarding the effect of birth weight on the risk of childhood abdominal obesity. In this study, we aimed to explore the association between birth weight and WHtR in Chinese children and adolescents, and to assess the correlations between birth weight and risk of abdominal obesity by sex and age group.

\section{Methods}

\section{Study design and data source}

Data in this study comes from the baseline crosssectional survey of a national multicenter clustercontrolled trial aimed to reduce the burden of obesity in children and adolescents (Registration number: NCT02343588). The survey was conducted in seven provinces or cities of China (Hunan, Ningxia, Tianjin, Chongqing, Liaoning, Shanghai, Guangzhou). Design and sampling procedure have been reported in detail elsewhere [25]. Briefly, a multi-stage cluster sampling method was used to select participants. At first, several regions were randomly selected from each province/city, and 12 to 16 schools were randomly chosen from each region. In each school, two classes were randomly selected in each grade and the whole class students were invited to participate in this survey. Those were recruited in this survey only after they and their parents signed informed consents voluntarily. All survey sites used the same protocol during the implementation process, and all processes of randomization were performed by a staff member who was not involved in the survey.

A total of 41,003 primary and middle school students aged 6-17 years old were enrolled in this study initially, of whom 30,486 remained in the analytical sample for the present work after excluding participants with missing records of urban/rural area $(n=234)$, weight $(n=$ $1387)$, height $(n=1630)$, waist circumference $(n=1786)$, birthdate $(n=2780)$ or birth weight $(n=3902)$. The trial was approved by the Ethical Committee of Peking University (IRB0000105213034), and all participating children and their parents signed the informed consent forms for the physical examination and questionnaire survey.

\section{Anthropometric measurement}

Anthropometric measurement was conducted by trained professional staff according to the standard protocol. Participants were asked to wear their underwear when waist circumference $(\mathrm{WC}, \mathrm{cm})$ and height $(\mathrm{cm})$ were measured. WC was measured at the midpoint between the iliac crest and lowest rib by Myotape scale (Accufitness, Green Villge, Colordo, USA) with $0.1 \mathrm{~cm}$ precision, and height was measured using the portable stadiometer (model TZG, Jiangyin Hongya Science and Education Equipment Co., Ltd.) with $0.1 \mathrm{~cm}$ precision. Both WC and height were measured twice and the average of two records was used in data analysis. Waist-to-height ratio (WHtR) was calculated as WC divided by the height. The cut-off value of 0.5 was used for WHtR to classify abdominal obesity [26].

\section{Questionnaire survey}

Students' questionnaire and parental questionnaire were used to collect the information from children and their parents, respectively.

The students' questionnaire was completed by themselves in children of grade 4 to 12 (with age range from 10 to 17 years old) and was completed under the assistance of their parents in children of grade 1 to 3 (with age range from 6 to 9 years old).

The students' questionnaire was used to collect information of dietary behavior, including the consumption of fruits, vegetables, total meat, and sugar-sweetened beverages (SSBs) over the past 7 days. A serving of fruit/ vegetable was defined as the size of an adult fist 
(approximately $120 \mathrm{~g}$ ) [27], a serving of SSBs was defined as a canned beverage (approximately $250 \mathrm{ml}$ ), and a portion of meat equals to the size of an adult's palm (approximately $100 \mathrm{~g}$ ) [28]. Students reported the frequency (days) and amount (servings) of food and drink intake per day, the daily dietary intake was estimated as follow: average daily intake $=($ days $\times$ servings in those days $) / 7$.

Information of child's physical activity was recorded by the International Physical Activity QuestionnaireShort (IPAQ-S) [29], which has been widely used in children and adolescents. All recruited students were asked to report the frequency (days) and duration (hours and minutes) of moderate to vigorous-intensity physical activities (MVPA) over the past 7 days, and the average daily time of MVPA was calculated as follow: average daily time $=($ days $\times$ duration in those days $) / 7$.

The parental questionnaire was filled out by parents at home. Paternal and maternal height and weight were reported in the parental questionnaire and then used to calculate body mass index (BMI), a cut-off point of $\mathrm{BMI} \geq 24 \mathrm{~kg} / \mathrm{m}^{2}$ was applied to define parental overweight/obesity. Parental educational level was classified into four categories (junior high school or below, senior high school, junior college, and college or above). Parents were required to report their children's early life information, including birth weight, gestational age and number of fetus (singleton, twice or more) based on the birth certificate or health clinic record [30]. If they did not have it, parents were asked to recall the birth weight based on their own measurements. About $70.9 \%$ of parents report the information of their children's early life based on the birth certificate or the health clinic card. Besides, information about feeding patterns (breastfeeding, not breastfeeding) and number of children (single child, two or more children) were additionally obtained. According to birth weight, participants were divided into five categories: <2500 g, 2500-2999 g, 3000-3499 g, $3500-3999 \mathrm{~g}$, and $\geq 4000 \mathrm{~g}$ [31].

\section{Statistical analysis}

Descriptive results were characterized as means \pm standard deviations for continuous variables and percentages for categorical variables. One-way ANOVA, independent sample Student's t-test and Chi-square test were used to compare the distribution of descriptive characteristics between boys and girls. The nonlinear association between birth weight and WHtR was performed by fractional polynomial regression model. Logistic regression models were performed to assess the odds ratios (ORs) and $95 \%$ confidence intervals (CIs) for abdominal obesity when participants with birth weight of 2500-2999 g were used as the reference group. The crude model was adjusted for sex (only in total group), residence area, and age, while the adjusted model was further adjusted for gestational age, delivery mode, fetus number, feeding pattern, single-child status, paternal overweight/obesity, maternal overweight/obesity, paternal educational level, maternal educational level, daily fruit and vegetable consumption, daily meat consumption, daily SSBs consumption, and daily moderate to vigorous physical activity. Since about $25.6 \%$ of the original study sample had to be excluded for a variety of reasons, a sensitive analysis was conducted in the initial sample of 41,003 children. In addition, we have also done a sensitive analysis by extracting participants with original birth weight records $(n=21,615)$. All analyses were conducted using SPSS 20.0 (IBM, NY, USA) and Stata 14 software (College Station, TX, USA) and a two-sided $P$ value of $<0.05$ was considered statistically significant.

\section{Results}

\section{Subject characteristics}

A total of 30,486 students aged 6-17 years were included in the analysis. As showed in Table 1, 52.1\% of the participants were boys, and $59.9 \%$ lived in urban areas. The mean birth weight was (3324.4 \pm 502.9) $\mathrm{g}$ in total participants, which was higher in boys $(3366.8 \pm 513.9 \mathrm{~g})$ than in girls $(3278.5 \pm 486.7 \mathrm{~g})$ $(P<0.01)$. The prevalence of abdominal obesity was $16.4 \%$ in total participants with a higher rate in boys $(20.5 \%)$ than that in girls $(12.0 \%)(P<0.05)$.

\section{The nonlinear relationship between birth weight and WHtR}

The nonlinear relationship of birth weight and WHtR is shown in Fig. 1. A J-shaped association was observed in the crude model. This association was slightly changed after further adjusting for confounding factors, with the range of birth weight associated with the lowest WHtR around $2500 \mathrm{~g}$. In the stratified analysis, similar patterns were detected both in boys and girls. However, the birth weight associated with the lowest WHtR in boys was lower than that in girls.

\section{Association between birth weight and risk of abdominal obesity in boys and girls}

Figure 2 shows the association between birth weight and risk of abdominal obesity in boys and girls. The crude model shows that compared with participants whose birth weight ranged from 2500 to $2999 \mathrm{~g}$, those who had higher birth weight (3000-3499 g, 3500-3999 g, $\geq 4000 \mathrm{~g}$ ) are associated with an elevated risk of abdominal obesity. Though lower ORs were detected in participants with birth weight $<2500 \mathrm{~g}$, especially in girls, the difference was not statistically significant $(P=0.692)$. When further adjusted for potential confounding factors, only minor changes were observed for these estimations. The birth weight $(\geq 3000 \mathrm{~g})$ was positively associated with higher 
Table 1 The characteristics of Chinese children and adolescents aged 7-17 years

\begin{tabular}{|c|c|c|c|c|}
\hline Variables & Total $(N=30,486)$ & Boys $(N=15,869)$ & Girls $(N=14,617)$ & $P$ value \\
\hline \multicolumn{5}{|l|}{ Residence area, $\mathrm{N}(\%)$} \\
\hline Urban & $18,255(59.9)$ & $9557(60.2)$ & $8698(59.5)$ & \multirow[t]{2}{*}{0.201} \\
\hline Rural & $12,231(40.1)$ & 6312(39.8) & $5919(40.5)$ & \\
\hline Age, years & $10.9 \pm 3.1$ & $10.8 \pm 3.1$ & $11.0 \pm 3.1$ & $<0.001$ \\
\hline \multicolumn{5}{|l|}{ Age group, $N(\%)$} \\
\hline $6-9$ & $12,252(40.2)$ & $6515(41.1)$ & $5737(39.2)$ & \multirow[t]{3}{*}{$<0.001$} \\
\hline $10-13$ & $11,818(38.8)$ & 6159(38.8) & $5659(38.7)$ & \\
\hline $14-17$ & $6416(21.0)$ & $3195(20.1)$ & $3221(22.0)$ & \\
\hline$W C, \mathrm{~cm}$ & $65.4 \pm 10.9$ & $66.6 \pm 11.7$ & $64.1 \pm 9.8$ & $<0.001$ \\
\hline Height, cm & $146.6 \pm 16.4$ & $147.7 \pm 17.8$ & $145.5 \pm 14.6$ & $<0.001$ \\
\hline WHtR & $0.45 \pm 0.05$ & $0.45 \pm 0.06$ & $0.44 \pm 0.05$ & $<0.001$ \\
\hline Abdominal obesity, N (\%) & $5006(16.4)$ & $3254(20.5)$ & $1752(12.0)$ & $<0.001$ \\
\hline Birth weight, $g$ & $3324.4 \pm 502.9$ & $3366.8 \pm 513.9$ & $3278.5 \pm 486.7$ & $<0.001$ \\
\hline \multicolumn{5}{|l|}{ Birth weight group, N (\%) } \\
\hline$<2500$ & $943(3.1)$ & $460(2.9)$ & 483(3.3) & \multirow[t]{5}{*}{$<0.001$} \\
\hline 2500-2999 & 4057(13.3) & 1865(11.8) & 2192(15.0) & \\
\hline 3000-3499 & $13,504(44.3)$ & 6649(41.9) & 6855(46.9) & \\
\hline 3500-3999 & $8834(29.0)$ & $4949(31.2)$ & $3885(26.6)$ & \\
\hline$\geq 4000$ & $3148(10.3)$ & 1946(12.3) & $1202(8.2)$ & \\
\hline Gestational age, weeks & $39.8 \pm 1.2$ & $39.7 \pm 1.3$ & $39.8 \pm 1.2$ & $<0.001$ \\
\hline \multicolumn{5}{|l|}{ Fetus number, N (\%) } \\
\hline Singleton & $29,421(97.4)$ & $15,315(97.4)$ & $14,106(97.4)$ & \multirow[t]{2}{*}{0.831} \\
\hline Twins or more & $778(2.6)$ & $408(2.6)$ & $370(2.6)$ & \\
\hline \multicolumn{5}{|l|}{ Breastfeeding, N (\%) } \\
\hline Breastfeeding & $25798(85.2)$ & $13,371(84.9)$ & $12,427(85.6)$ & 0.075 \\
\hline Single child N (\%) & $20,371(66.8)$ & $11,264(71.0)$ & $9107(62.3)$ & $<0.001$ \\
\hline Paternal overweight/obesity, N (\%) & $15,052(49.4)$ & $7953(50.1)$ & 7099(48.6) & $<0.001$ \\
\hline Maternal overweight/obesity, N (\%) & $7076(23.2)$ & $3632(22.9)$ & $3444(23.6)$ & 0.164 \\
\hline \multicolumn{5}{|l|}{ Paternal educational level, N (\%) } \\
\hline Junior high school or blew & $12,948(42.7)$ & $6780(43.0)$ & $6168(42.4)$ & \multirow[t]{4}{*}{0.767} \\
\hline Senior high school & $8468(27.9)$ & 4395(27.9) & 4073(28.0) & \\
\hline Junior college & $4465(14.7)$ & $2310(14.7)$ & 2155(14.8) & \\
\hline College or above & $4424(14.6)$ & $2282(14.5)$ & $2142(14.7)$ & \\
\hline \multicolumn{5}{|l|}{ Maternal educational level, N (\%) } \\
\hline Junior high school or blew & $14,214(47.0)$ & $7454(47.4)$ & $6760(46.5)$ & \multirow[t]{4}{*}{0.427} \\
\hline Senior high school & $7940(26.2)$ & 4076(25.9) & $3864(26.6)$ & \\
\hline Junior college & $4462(14.7)$ & 2305(14.6) & 2157(14.9) & \\
\hline College or above & $3648(12.1)$ & 1904(12.1) & 1744(12.0) & \\
\hline Daily fruit and vegetable consumption, servings & $3.2 \pm 2.1$ & $3.2 \pm 2.1$ & $3.2 \pm 2.0$ & 0.638 \\
\hline Daily SSBs consumption, servings & $0.4 \pm 0.7$ & $0.5 \pm 0.8$ & $0.3 \pm 0.6$ & $<0.001$ \\
\hline Daily meat consumption, servings & $1.2 \pm 1.2$ & $1.3 \pm 1.3$ & $1.0 \pm 1.0$ & $<0.001$ \\
\hline Daily moderate to vigorous physical activity duration, hours & $0.7 \pm 1.0$ & $0.8 \pm 1.1$ & $0.7 \pm 1.0$ & $<0.001$ \\
\hline
\end{tabular}

Notes: WC Waist circumference; WHtR Waist-to-height ratio; SSBs Sugar-sweetened beverages 

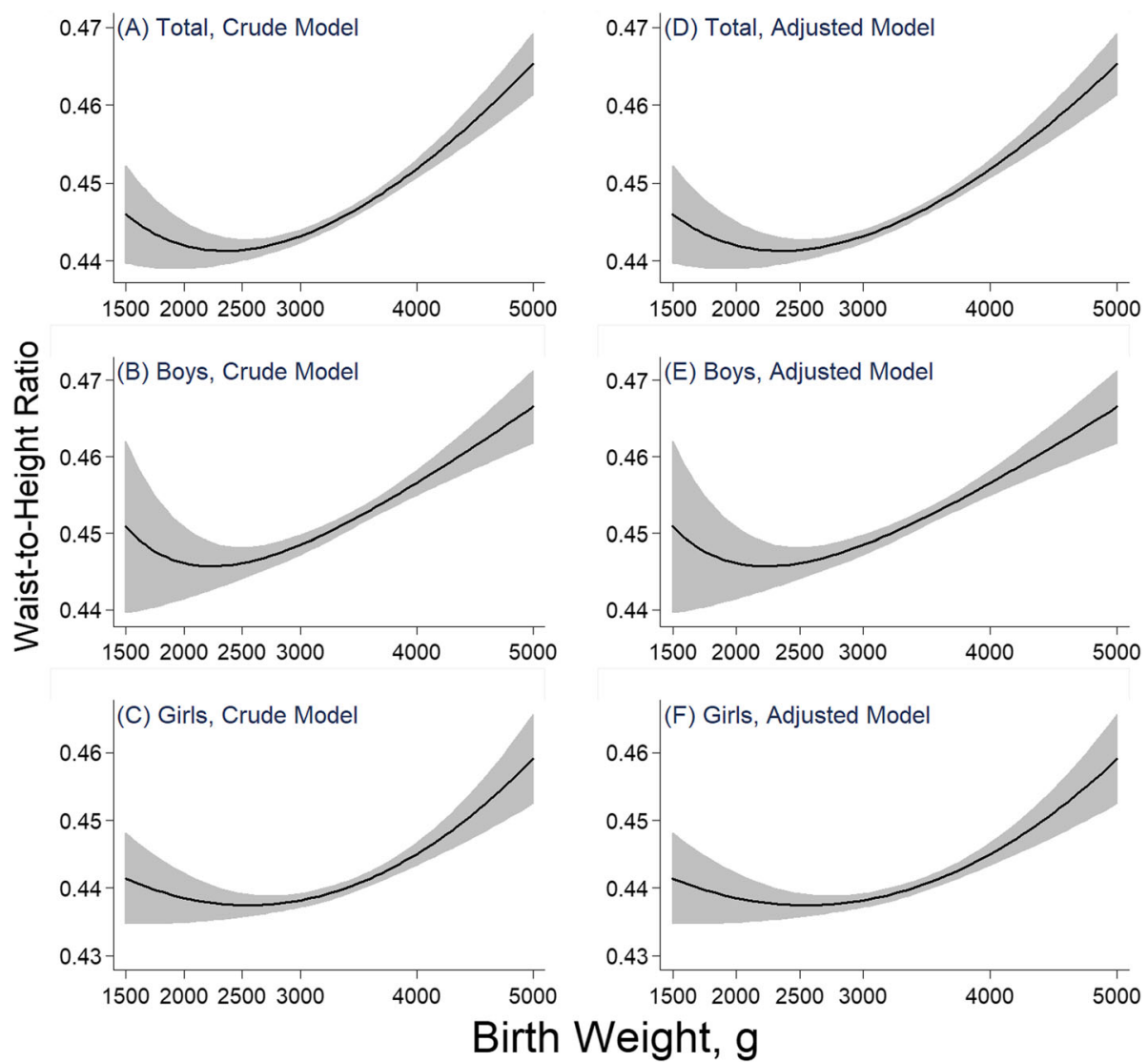

Fig. 1 The relationship between birth weight and WHtR in children and adolescents. Notes: the crude model was adjusted for sex (only in total group), residence area, and age; the adjusted model was futher adjusted for gestational age, delivery mode, fetus number, feeding pattern, single-child or not, paternal overweight/obesity, maternal overweight/obesity, paternal educational level, maternal educational level, daily fruit and vegetable consumption, daily meat consumption, daily SSBs consumption, daily moderate to vigorous physical activity

risk of abdominal obesity (for 3000-3499 g: OR[95\% CI] = $1.13[1.01,1.25]$; for $3500-3999 \mathrm{~g}$ : OR[95\% CI] = 1.22[1.09, $1.37]$; for $\geq 4000 \mathrm{~g}$ : OR[95\% CI] $=1.50[1.31,1.71])$. In addition, the ORs of abdominal obesity were higher in boys than those in girls in the same birth weight group. Participants had an evelated risk for those with a birth weight $\geq 3000 \mathrm{~g}$ in boys and $\geq 4000 \mathrm{~g}$ in girls. Based on the original sample $(n=41,003)$ and original birth record sample $(n=21,615)$, we have done two sensitive analyses and have come to similar results with the present study (Table S1 and Table S3).

\section{Association between birthweight and risk of abdominal obesity in different age groups}

To investigate whether the association varied among age groups, participants were divided into three groups according to their ages. Table 2 shows that high birth weight was related to abdominal obesity regardless of the age groups. Participants with birth weight $\geq 4000 \mathrm{~g}$ had higher risk of abdominal obesity in all three age groups, with the ORs ranging from 1.27 (95\% CI: $1.03-1.58$ ) to 1.59 (95\% CI: $1.29-1.97$ ).
Participants with birth weight between 3000 and $3999 \mathrm{~g}$ also showed an elevated risk, though the statistically significant result was only found in children aged 6-9 years. In addition, across the age groups, no significant association between low birth weight $(<2500 \mathrm{~g})$ and abdominal obesity was found. Based on the original sample $(n=41,003)$ and original birth record sample $(n=21,615)$, we have done two sensitive analyses and have come to similar results with the present study. (Table S2 and Table S4).

\section{Discussion}

In this study of 30,486 Chinese children and adolescents, the prevalence of abdominal obesity is $16.4 \%$, the rate was lower than data from Spanish (21.3\%) [32], but higher than results of Australian children in 2015 (14.6\%) [33]. The reasons for the difference are complicated and variations of ethnicity, dietary behavior, lifestyle and economic development may contribute to it $[32,33]$. Our study indicated that boys were more likely to have abdominal obesity than girls, which is in line with several previous studies [32, 33]. 
Crude model
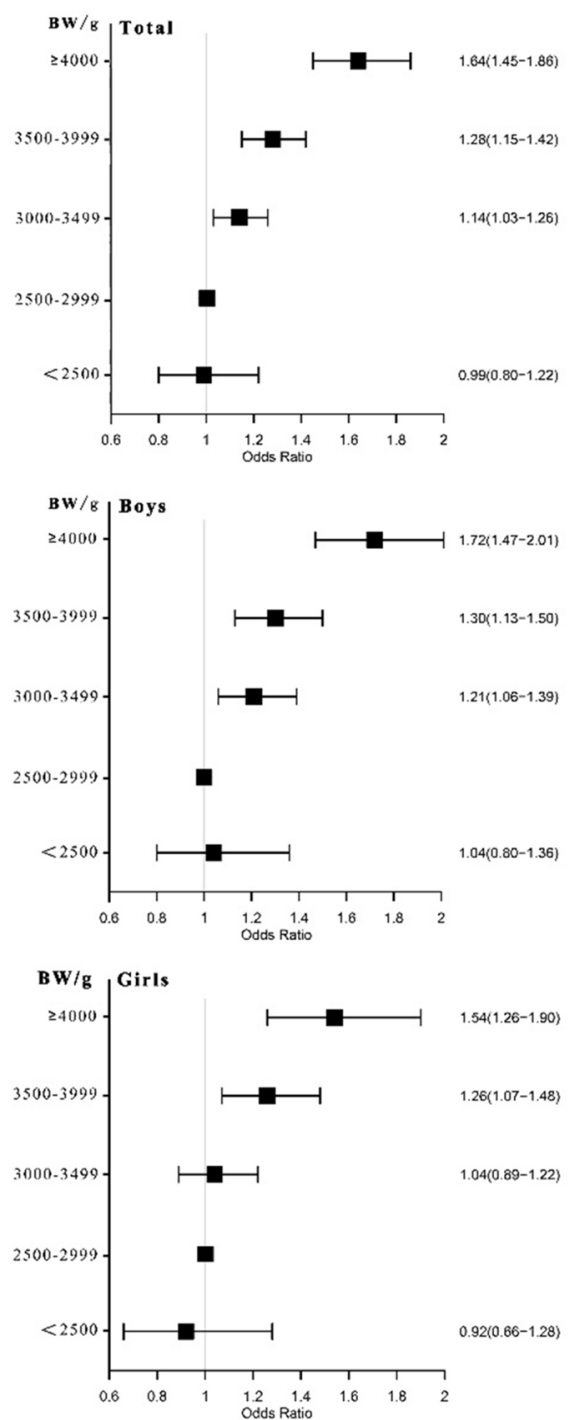

Adjusted model
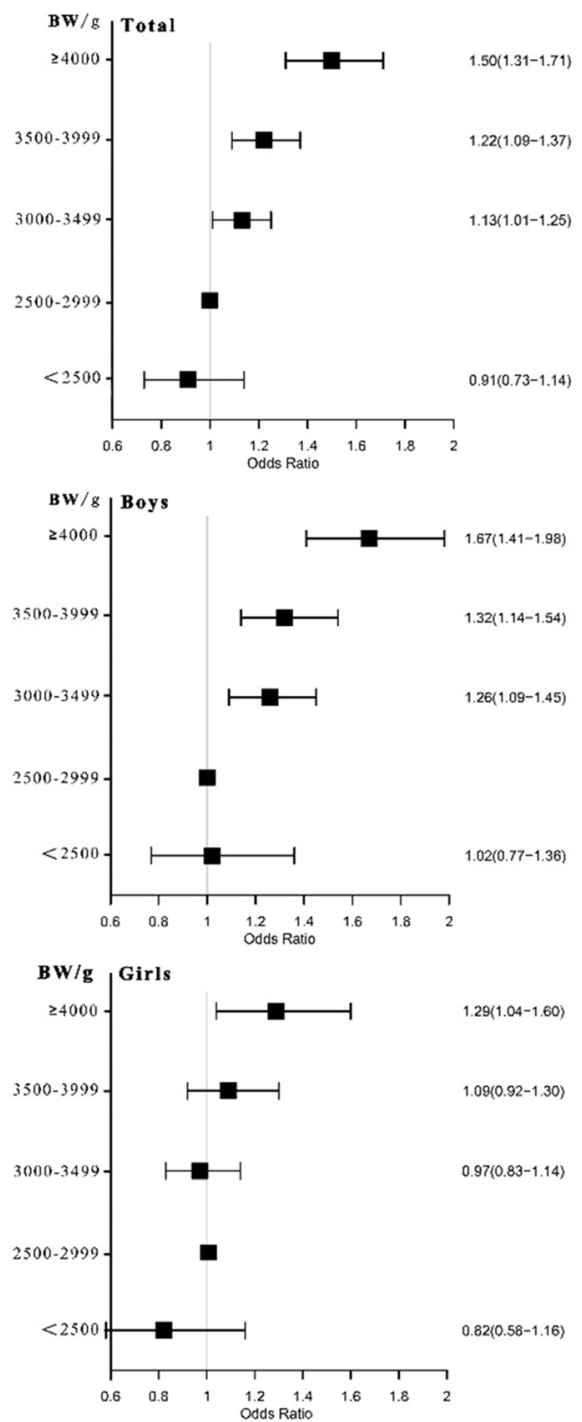

Fig. 2 Risk of childhood abdominal obesity in boys and girls with different birth weights. Notes: crude model was adjusted for sex (only in total group), residence area, and age; the adjusted model was further adjusted for gestational age, fetus number, feeding pattern, single-child or not, paternal overweight/obesity, maternal overweight/obesity, paternal educational level, maternal educational level, daily fruit and vegetable consumption, daily meat consumption, daily SSBs consumption, daily moderate to vigorous physical activity on the basic of crude model

Table 2 Associations between birth weight and childhood abdominal obesity in different age groups

\begin{tabular}{|c|c|c|c|c|c|c|c|c|c|}
\hline \multirow{2}{*}{$\begin{array}{l}\text { Birth } \\
\text { weight } \\
\text { groups }\end{array}$} & \multicolumn{3}{|c|}{ 6-9 years old } & \multicolumn{3}{|c|}{$10-13$ years old } & \multicolumn{3}{|c|}{ 14-17 years old } \\
\hline & $\mathrm{N}$ & OR(95\% Cl) & $P$ value & $\mathrm{N}$ & $\mathrm{OR}(95 \% \mathrm{Cl})$ & $P$ value & $\mathrm{N}$ & $\mathrm{OR}(95 \% \mathrm{Cl})$ & $P$ value \\
\hline$\geq 4000$ & 1153 & 1.59(1.29-1.97) & $<0.001$ & 1175 & $1.27(1.03-1.58)$ & 0.006 & 820 & $1.52(1.12-2.07)$ & 0.006 \\
\hline 3500-3999 & 3411 & $1.23(1.03-1.46)$ & 0.009 & 3540 & $1.14(0.96-1.36)$ & 0.082 & 1883 & $1.29(0.98-1.69)$ & 0.055 \\
\hline 3000-3499 & 5635 & $1.08(0.91-1.27)$ & 0.297 & 5167 & $1.14(0.96-1.34)$ & 0.099 & 2702 & $1.18(0.91-1.53)$ & 0.202 \\
\hline 2500-2999 & 1647 & Reference & & 1600 & Reference & & 810 & Reference & \\
\hline$<2500$ & 406 & $0.81(0.58-1.15)$ & 0.249 & 336 & $0.83(0.57-1.20)$ & 0.340 & 201 & $1.40(0.87-2.26)$ & 0.174 \\
\hline
\end{tabular}

Notes: The model was adjusted for sex, residence area, gestational age, fetus number, feeding pattern, single-child or not, paternal overweight/obesity, maternal overweight/obesity, paternal educational level, maternal educational level, daily fruit and vegetable consumption, daily meat consumption, daily SSBs consumption and daily moderate to vigorous physical activity 
A J-shaped relationship was observed between birth weight and WHtR in this study. On the one hand, a positive association between birth weight and WHtR was found in children with birth weight $>3000 \mathrm{~g}$, especially in boys. These findings were consistent with studies conducted by Schellong [34], Loaiza [35] and Kang [36]. One possible reason for this may be the sexual difference in growth of body composition, bone, and muscle growth during prenatal period [37, 38].

Additionally, the present study found that low birth weight $(<2500 \mathrm{~g})$ was not significantly associated with risk of abdominal obesity regardless of sex and age. Studies from Frye [39], Yuan [31] and Singhal [40] had also demonstrated similar conclusion that low birth weight was not a risk factor of obesity, they point that children who born in unfavorable nutritional conditions may have permanent influence in later life. Yuan [31] found children with extremely low birth weight (less than $1500 \mathrm{~g}$ ) had slightly higher risk of abdominal obesity, even though low birth weight (2000-2499 g, 1500$1999 \mathrm{~g}$ ) was not significant related with abdominal obesity. A cohort study conducted by Vohr BR [20] et al. had also come to similar conclusions, in that extreme preterm infant had increased rate of abdominal obesity. One explanation is that infants who are born with a low birth weight tend to experience a later catch-up growth, which leads to higher risk of abdominal obesity in later years [41].

The association between birth weight and abdominal obesity may be explained by intrauterine environmental condition, genetic and lifestyle factors. Birth weight is regarded as a reflection of the intrauterine environmental situation [42]. On the one hand, over nutrition and malnutrition during pregnancy can have effects on birth weight, and this environmental exposure can induce persistent alterations in the epigenome, which leads to an increased risk of obesity in later life. On the other hand, it has been found that the number of muscle cells in the body is influenced by birth weight, that is, infants with higher birth weight had greater number of cells in both adipose and non-adipose tissues [43], which could persist later in life. Furthermore, genetic factors may also influence the fat accumulation in childhood. Sharp's study [44] found that low birth weight affects the neonatal epigenome via DNA methylation. Further, Lin [45] suggested that developmental pathways to adiposity begin before birth and are influenced by genetic and epigenetic factors. Previous studies have also demonstrated that birth weight was associated with later exercise capacity or physical activity performance. Andersen and colleagues [46] found that adolescents with high birth weight had lower physical activity level.

Extending the findings of previous studies, we have further conducted an analysis by different age group.
While high birth weight (>4000 g) was significantly associated with abdominal obesity in all age groups, elevated risk of abdominal obesity was also observed in birth weight group of 3500-3999 g, but only in those of younger ages (6-9 years). A possible explanation for this is that the effects were influenced by other environmental factors which were not considered in this study, for example, it has been reported that younger children spend more time in doors than older children, and they are less sensitive to unhealthy food outside of the home than older children [47], and more environmental factors could affect abdominal obesity in adolescents within older age group [48].

There are several limitations in this study. First, the birth weight information was obtained from parental questionnaire, rather than directly from the hospital birth records database, and nearly 30\% children's birth weight were obtained by parental recall. Second, this study was based on a cross-sectional study, and no causal relationship can be suggested. In addition, we did not have the information of parental nutritional status during pregnancy. It has been suggested that gestational weight gain could lead to fetal macrosomia and obesity after birth. Future study is needed to determine the relationship between birth weight and other health consequences in later life.

\section{Conclusion}

In summary, this study examined the association between birth weight and risk of abdominal obesity in Chinese children and adolescents aged 6-17 years old. A J-shaped relationship was found between birth weight and WHtR, and children with high birth weight $(>3000$ g) had higher risk of abdominal obesity than those with low birth weight, especially in boys. This study would contribute to a better understanding of the relationship between intrauterine growth and abdominal obesity in later life. Our findings could aid the clinical practitioners to identify youth at risk of abdominal obesity, and have a potential to improve intervention strategies aimed at reducing the burden of childhood obesity. Further study is needed to explore the mechanisms underlying this association.

\section{Supplementary information}

Supplementary information accompanies this paper at https://doi.org/10. 1186/s12889-020-09456-0.

Additional file 1: Table S1. Risk of childhood abdominal obesity in boys and girls with different birth weights in Total participants ( $N=$ 41,003). Table S2. Associations between birth weight and childhood abdominal obesity in different age groups. Table S3. Risk of childhood abdominal obesity in boys and girls with different birth weights in participants with original birth weight records $(N=21,615)$. Table S4. 
Associations between birth weight and childhood abdominal obesity in participants with original birth weight records, stratified by age groups

\section{Acknowledgements}

We would like to thank the participants and the research staff for data collection.

\section{Conflict of interest}

The authors declared no conflict of interest.

\section{Authors' contributions}

All authors contribute in conceive, design of this study. ZY, XW and YD performed the data analysis, DG, YL, BD and ZZ interpreted, wrote and finalized the manuscript, YS, JM and LA participate in the reviewing and revising the manuscript. All authors read and approved the final manuscript.

\section{Funding}

This study was granted by the Research Special Fund for Public Welfare Industry of Health (201202010) awarded to Jun Ma and the Excellent Talents Fund Program of Peking University Health Science Center (BMU2017YJ002) awarded to Bin Dong. These funding sources had no role in the design of this study and did not have any role during its execution, analyses, interpretation of the data, or decision to submit results.

\section{Availability of data and materials}

The datasets generated during and/or analyzed during the current study are not publicly available due to confidentiality of data and subsequent research, but are available from the corresponding author on reasonable request.

\section{Ethics approval and consent to participate}

The 1147 project was approved by the Ethical Committee of Peking University (IRB0000105213034), and all participating children and their parents have signed the informed consent forms for the physical examination and questionnaire survey.

\section{Consent for publication}

Not applicable.

\section{Competing interests}

None of the authors have any competing interests.

\section{Author details}

'Institute of Child and Adolescent Health \& School of Public Health, Peking University, No. 38 Xueyuan Road, Haidian District, Beijing 100191, People's Republic of China. ${ }^{2}$ Department of Commissioning, South Western Sydney Primary Health Network, Campbelltown, Australia.

\section{Received: 21 August 2019 Accepted: 26 August 2020}

\section{Published online: 10 November 2020}

\section{References}

1. Collaboration NCDRF. Worldwide trends in body-mass index, underweight, overweight, and obesity from 1975 to 2016: a pooled analysis of 2416 population-based measurement studies in 128.9 million children, adolescents, and adults. Lancet. 2017:390(10113):2627-42.

2. Sun H, Ma Y, Han D, Pan CW, Xu Y. Prevalence and trends in obesity among China's children and adolescents, 1985-2010. PLoS One. 2014; 9(8):e105469.

3. Wang S, Dong YH, Wang ZH, Zou Z, Ma J. Trends in overweight and obesity among Chinese children of 7-18 years old during 1985-2014. Zhonghua Yu Fang Yi Xue Za Zhi. 2017;51(4):300-5.

4. Ren J, Wu J, Ji M, Rong F, Li Y, Gao E, et al. The effect of high birth weight on overweight and obesity in childhood and adolescence. A cohort study in China. Saudi Med J. 2013;34(6):623-31.

5. Freedman DS, Katzmarzyk PT, Dietz WH, Srinivasan SR, Berenson GS. Relation of body mass index and skinfold thicknesses to cardiovascular disease risk factors in children: the Bogalusa heart study. Am J Clin Nutr. 2009:90(1):210-6.

6. Prentice AM, Jebb SA. Beyond body mass index. Obes Rev. 2001;2(3):141-7.
7. Tomaszewski P, Zmijewski P, Milde K, Sienkiewicz-Dianzenza E. Weightheight relationships and central obesity in 7-year-old to 10-year-old polish urban children: a comparison of different BMI and WHtR standards. J Physiol Anthropol. 2015;34:34.

8. Czernichow S, Kengne AP, Stamatakis E, Hamer M, Batty GD. Body mass index, waist circumference and waist-hip ratio: which is the better discriminator of cardiovascular disease mortality risk?: evidence from an individual-participant meta-analysis of 82864 participants from nine cohort studies. Obes Rev. 2011;12(9):680-7.

9. Ashwell M, Gunn P, Gibson S. Waist-to-height ratio is a better screening tool than waist circumference and BMI for adult cardiometabolic risk factors: systematic review and meta-analysis. Obes Rev. 2012;13(3):275-86.

10. Brambilla P, Bedogni G, Heo M, Pietrobelli A. Waist circumference-to-height ratio predicts adiposity better than body mass index in children and adolescents. Int J Obes. 2013;37(7):943-6.

11. Nakai M, Watanabe M, Nishimura K, Igashiyama AH, Takegami M, Kokubo Y, et al. comparison of body mass index with waist circumference, waist-toheight ratio and waist-to-hip ratio as a predictor of incident hypertension in Japan. Hypertension. 2014;64.

12. Kahn HS, Imperatore G, Cheng YJ. A population-based comparison of BMI percentiles and waist-to-height ratio for identifying cardiovascular risk in youth. J Pediatr. 2005;146(4):482-8.

13. Yoo EG. Waist-to-height ratio as a screening tool for obesity and cardiometabolic risk. Korean J Pediatr. 2016;59(11):425-31.

14. Hales CN, Barker DJ. The thrifty phenotype hypothesis. Br Med Bull. 2001;60:5-20.

15. Hanson M, Godfrey KM, Lillycrop KA, Burdge GC, Gluckman PD. Developmental plasticity and developmental origins of non-communicable disease: theoretical considerations and epigenetic mechanisms. Prog Biophys Mol Biol. 2011;106(1):272-80.

16. Oken E, Gillman MW. Fetal origins of obesity. Obes Res. 2003;11(4):496-506.

17. Camerota M, Bollen KA. Birth weight, birth length, and gestational age as indicators of favorable fetal growth conditions in a US sample. PLoS One. 2016;11(4):e0153800

18. Ansari H, Qorbani M, Rezaei F, Djalalinia S, Asadi M, Miranzadeh S, et al. Association of birth weight with abdominal obesity and weight disorders in children and adolescents: the weight disorder survey of the CASPIAN-IV study. J Cardiovasc Thorac Res. 2017;9(3):140-6.

19. Tian JY, Cheng Q, Song XM, Li G, Jiang GX, Gu YY, et al. Birth weight and risk of type 2 diabetes, abdominal obesity and hypertension among Chinese adults. Eur J Endocrinol. 2006;155(4):601-7.

20. Vohr BR, Heyne R, Bann CM, Das A, Higgins RD, Hintz SR, et al. Extreme preterm infant rates of overweight and obesity at school age in the SUPPORT neuroimaging and neurodevelopmental outcomes cohort. $J$ Pediatr. 2018:200:132-9 e3.

21. Barker M, Robinson S, Osmond C, Barker DJ. Birth weight and body fat distribution in adolescent girls. Arch Dis Child. 1997;77(5):381-3.

22. Rodriguez Vargas N, Fernandez-Britto JE, Martinez Perez TP, Martinez Garcia R, Castaneda Garcia CM, Garriga Reyes M, et al. Waist-height ratio in children of 7 to 11 years with high weight at birth and its relationship with gender, age and diet. Clin Investig Arterioscler. 2018; 30(4):155-62.

23. Rossi CE, de Vasconcelos Fde A. Relationship between birth weight and overweight/obesity among students in Florianopolis, Santa Catarina, Brazil: a retrospective cohort study. Sao Paulo Med J. 2014;132(5):273-81.

24. Harada K, Saruwatari A, Kitaoka K, Aoi W, Wada S, Ohkubo T, et al. Low birth weight is associated with high waist-to-height ratio in Japanese elementary school girls. Tohoku J Exp Med. 2013;231(2):85-91.

25. Chen Y, Ma L, Ma Y, Wang H, Luo J, Zhang $X$, et al. A national schoolbased health lifestyles interventions among Chinese children and adolescents against obesity: rationale, design and methodology of a randomized controlled trial in China. Bmc Public Health. 2015;15:210.

26. Nawarycz T, So HK, Choi KC, Sung RY, Li AM, Nelson EA, et al. Waist-toheight ratio as a measure of abdominal obesity in southern Chinese and European children and adolescents. Int J Obes. 2016;40(7):1109-18.

27. Volken T, Ruesch P, Guggisberg J. Fruit and vegetable consumption among migrants in Switzerland. Public Health Nutr. 2013;16(1):156-63.

28. Hicks TM, Knowles SO, Farouk MM. Global provisioning of red meat for Flexitarian diets. Front Nutr. 2018:5:50

29. Lee PH, Macfarlane DJ, Lam TH, Stewart SM. Validity of the international physical activity questionnaire short form (IPAQ-SF): a systematic review. Int J Behav Nutr Phys Act. 2011;8:115. 
30. Zou Z, Yang Z, Yang Z, Wang X, Gao D, Dong Y, et al. Association of high birth weight with overweight and obesity in Chinese students aged 6-18 years: a national, cross-sectional study in China. BMJ Open. 2019;9(5): e024532.

31. Yuan ZP, Yang M, Liang L, Fu JF, Xiong F, Liu GL, et al. Possible role of birth weight on general and central obesity in Chinese children and adolescents: a cross-sectional study. Ann Epidemiol. 2015;25(10):748-52.

32. Schroder H, Ribas L, Koebnick C, Funtikova A, Gomez SF, Fito M, et al. Prevalence of abdominal obesity in Spanish children and adolescents. Do we need waist circumference measurements in pediatric practice? Plos One. 2014;9(1):e87549.

33. Hardy LL, Mihrshahi S, Gale J, Drayton BA, Bauman A, Mitchell J. 30-year trends in overweight, obesity and waist-to-height ratio by socioeconomic status in Australian children, 1985 to 2015. Int J Obes. 2017;41(1):76-82.

34. Schellong K, Schulz S, Harder T, Plagemann A. Birth weight and long-term overweight risk: systematic review and a meta-analysis including 643,902 persons from 66 studies and 26 countries globally. PLoS One. 2012;7(10):e47776.

35. Loaiza S, Atalah E. Birth weight and obesity risk at first grade of high school in a non-concurrent cohort of Chilean children. Public Health Nutr. 2013; 16(2):228-32.

36. Kang M, Yoo JE, Kim K, Choi S, Park SM. Associations between birth weight, obesity, fat mass and lean mass in Korean adolescents: the fifth Korea National Health and nutrition examination survey. BMJ Open. 2018;8(2): e018039.

37. Wells JC. Sexual dimorphism of body composition. Best Pract Res Clin Endocrinol Metab. 2007:21(3):415-30.

38. Veldhuis JD, Roemmich JN, Richmond EJ, Rogol AD, Lovejoy JC, SheffieldMoore $\mathrm{M}$, et al. Endocrine control of body composition in infancy, childhood, and puberty. Endocr Rev. 2005;26(1):114-46.

39. Frye $\mathrm{C}$, Heinrich J. Trends and predictors of overweight and obesity in east German children. Int J Obes Relat Metab Disord. 2003;27(8):963-9.

40. Singhal A, Wells J, Cole TJ, Fewtrell M, Lucas A. Programming of lean body mass: a link between birth weight, obesity, and cardiovascular disease? Am J Clin Nutr. 2003;77(3):726-30.

41. Ong KK, Ahmed ML, Emmett PM, Preece MA, Dunger DB. Association between postnatal catch-up growth and obesity in childhood: prospective cohort study. BMJ. 2000:320(7240):967-71.

42. van Dijk SJ, Molloy PL, Varinli H, Morrison JL, Muhlhausler BS, Members of Epi S. Epigenetics and human obesity. Int J Obes. 2015;39(1):85-97.

43. Jelenkovic A, Yokoyama Y, Sund R, Pietilainen KH, Hur YM, Willemsen G, et al. Association between birthweight and later body mass index: an individual-based pooled analysis of 27 twin cohorts participating in the CODATwins project. Int J Epidemiol. 2017:46(5):1488-98.

44. Sharp GC, Lawlor DA, Richmond RC, Fraser A, Simpkin A, Suderman M, et al. Maternal pre-pregnancy BMl and gestational weight gain, offspring DNA methylation and later offspring adiposity: findings from the Avon longitudinal study of parents and children. Int J Epidemiol. 2015;44(4):1288-304.

45. Lin X, Lim IY, Wu Y, Teh AL, Chen L, Aris IM, et al. Developmental pathways to adiposity begin before birth and are influenced by genotype, prenatal environment and epigenome. BMC Med. 2017;15(1):50.

46. Andersen LG, Angquist L, Gamborg M, Byberg L, Bengtsson C, Canoy D, et al. Birth weight in relation to leisure time physical activity in adolescence and adulthood: meta-analysis of results from 13 nordic cohorts. PLoS One. 2009;4(12):e8192.

47. Yang Y, Jiang Y, Xu Y, Mzayek F, Levy M. A cross-sectional study of the influence of neighborhood environment on childhood overweight and obesity: variation by age, gender, and environment characteristics. Prev Med. 2018;108:23-8.

48. Nesbit KC, Kolobe TH, Sisson SB, Ghement IR. A structural equation model of environmental correlates of adolescent obesity for age and gender groups. Pediatr Obes. 2015;10(4):288-95.

\section{Publisher's Note}

Springer Nature remains neutral with regard to jurisdictional claims in published maps and institutional affiliations.

\section{Ready to submit your research? Choose BMC and benefit from:}

- fast, convenient online submission

- thorough peer review by experienced researchers in your field

- rapid publication on acceptance

- support for research data, including large and complex data types

- gold Open Access which fosters wider collaboration and increased citations

- maximum visibility for your research: over $100 \mathrm{M}$ website views per year

At BMC, research is always in progress.

Learn more biomedcentral.com/submissions 